University of Massachusetts Amherst

ScholarWorks@UMass Amherst

Published Work

Center for Student Success Research

2016

\title{
Student Affairs Professionals Supporting Students with Disabilities: A Grounded Theory Model
}

Ezekiel Kimball

University of Massachusetts Amherst

Annemarie Vaccaro

University of Rhode Island

Nadia Vargas

University of Massachusetts Amherst

Follow this and additional works at: https://scholarworks.umass.edu/cfssr_publishedwork

Part of the Disability and Equity in Education Commons, Higher Education Commons, and the Student Counseling and Personnel Services Commons

\section{Recommended Citation}

Kimball, Ezekiel; Vaccaro, Annemarie; and Vargas, Nadia, "Student Affairs Professionals Supporting Students with Disabilities: A Grounded Theory Model" (2016). Journal of Student Affairs Research and Practice. 4.

https://doi.org/10.1080/19496591.2016.1118697 
Student Affairs Professionals Supporting Students with Disabilities: A Grounded Theory Model

Ezekiel Kimball, University of Massachusetts Amherst

Annemarie Vaccaro, University of Rhode Island

Nadia Vargas, University of Massachusetts Amherst

This paper is a pre-publication draft of a forthcoming manuscript from the Journal of Student Affairs Research \& Practice. Please do not cite, reproduce, or distribute this piece without first contacting the corresponding author (ekimball@educ.umass.edu). 
The number of students with disabilities enrolled at postsecondary institutions has grown rapidly since the passage of the Americans with Disabilities Act in 1990 (United States Government Accountability Office, 2009). Nonetheless, students with disabilities are still significantly less likely than their peers to access higher education or to complete a baccalaureate degree (Hitchings, Retish, \& Horvath, 2005). This discrepancy represents a pressing equity challenge for student affairs professionals, who have long been concerned with creating equitable outcomes for students (Reason \& Broido, 2011). To date, only two studies have examined how prepared student affairs professionals are to support students with disabilities (Preece, Roberts, Beecher, Rash, Shwalb, \& Martinelli, 2007; Belch \& Marshak, 2006). Absent empirical findings, best practice literature is based largely on lessons learned from practice and personal experiences (e.g., Evans, Assadi, \& Herriott, 2005; Vance, Lipsitz \& Parks, 2014). As a result, student affairs professionals must support a minoritized population using informal theories drawn from disparate knowledge bases and personal experience (Reason \& Kimball, 2012). To introduce much needed empirical literature into this conversation, our work addresses two linked research questions: 1) How do student affairs professionals think about disability? - and - 2) What role does this thinking play in the strategies they use to support students with disabilities?

\section{Literature Review}

Literature concerning the experiences of students with disabilities is vast (Kimball, Wells, Ostiguy, Manly, \& Lauterbach, in press) but has been absent from top higher education journals (Peña, 2014). As a result, limited literature on the way that higher education professionals generally and student affairs professionals specifically conceptualize and respond to disability has been produced. We review literature related to major theoretical approaches to 
disability and empirical findings regarding stigma that illuminate how faculty, staff, and student attitudes towards disability impact the experience of students with disabilities.

\section{Theoretical Approaches}

There are many different theoretical perspectives on disability (e.g., moral, social justice), but the two most often seen in higher education practice and scholarship are the medical and social construction models. The medical approach regards disability as an ailment that must be "treated" to allow a person with disability to participate fully within society (Shakespeare, 2012; Swain \& French, 2000). This conception of disability problematizes the individual and thereby runs the risk of stigmatizing disability (Abberley, 1987). In comparison, if disability is viewed as a social construction, society instead becomes the problematic component in disability (Shakespeare, 2012; Swain \& French, 2000). That is, disabilities are only seen to exist when physical, social, and mental worlds are constructed in ways that allow certain people to participate and not others (Jones, 1996).

While higher education literature does not always clearly identify what model of disability it utilizes (Kimball et al., in press), legal definitions of disability typically use the medical definition as the baseline for compliance and the social constructionist viewpoint as the ideal (Kaplin \& Lee, 2013). This framing often means that the medical view is the default perspective adopted by practitioners who lack a full understanding of the law and wish to avoid

breaking it. Since studies have shown limited legal awareness among academic advisors (Preece et al., 2007) and senior student affairs officers (Belch \& Marshak, 2006), there is good reason to be skeptical about how widely the social construction perspective is being used.

\section{Disability Stigma}


In addition to a complex legal environment, students with disabilities experience the campus climate differently than do peers without disabilities due to pervasive stigma (Eilola et al., 2011; Lombardi \& Murray, 2011). Studies focused on faculty perceptions have revealed that this stigma can be reduced through evidence-based programs (Buchanan et al., 2010; Junco \& Salter, 2004). Only case study research has explored whether the same would be true for student affairs professionals (Evans et al., 2005), but existing literature indicates that the way that student affairs professionals think about student experience impacts practice more generally (Reason \& Kimball, 2012). Faculty with positive perceptions of students with disabilities are also more likely to adopt effective practices (Cook et al., 2009; Lombardi \& Murray, 2011).

Among these positive practices, the use of universal design principles has the potential to radically transform the experiences of students with disabilities (Izzo, Murray, \& Novak, 2008). Universal design refers to the design of environments, programs, services, and products so they are "welcoming and useful to groups that are diverse in many dimensions, including gender, race and ethnicity, age, socio-economic status, ability, disability, and learning style" (Burgstahler, 2008, p. 37). The seven principles associated with universal design include: equitable use, flexibility in use, simple and intuitive use, perceptible information, tolerance of error, low physical effort, size and space for approach and use (The Center for Universal Design, 1997). In short, universal design makes environmental interventions rather than by "treating" people with disabilities. Unfortunately, no empirical studies have documented if, or how, student affairs professionals understand and/or implement universal design principles.

\section{Methods}

Design. This study utilized an action-based, constructivist grounded theory framework (Charmaz, 2006) for the collection and analysis of focus group data (Morgan, 1996; Hernandez, 
2011). We incorporated data collection and initial analyses into a professional development opportunity for participants. The majority of our project ( 6 focus groups) took place at a NASPA regional conference. One additional focus group and one peer debriefing were conducted following the conference —one at a small, private liberal arts college and the other at a medium-sized, public research university. Though the use of the conference setting is a novel contribution of our research, action research has previously been shown effective when examining participant understandings of disability (Eilola et al., 2011).

We used an introductory conference session to provide an overview of our project. On the second and third days of the conference, we conducted six focus groups-including participants who had, and had not, attended the introductory session. We closed each focus group with time for debriefing about both the process and content of the focus group conversations. We also invited participants to attend a presentation on the final day of the conference where would reveal preliminary analyses. In this closing workshop session, we reviewed relevant literature, presented our preliminary findings, and once again offered space for participant debriefing. Following the conference, we conducted one additional focus group and one debriefing session to explore the extent to which our findings were produced by the conference context.

Focus Groups Methods. Our focus group facilitation utilized a loosely structured protocol—allowing the focus group facilitator to listen for, and respond to, emergent group interest (Morgan, 1996). Our protocol design ensured that each focus group spent some time on several key questions. While the sequencing and precise phrasing varied from focus group-tofocus group, the questions included: 1) How do you define disability? 2) What role does thinking about people with disabilities play in your work? 3) Tell us about your experiences with disability or with people with disabilities. 4) What people and offices provide support for 
students with disabilities or leadership on disability-related issues? 5) What obstacles exist on your campus in working with students with disabilities? While the facilitator concentrated primarily on managing conversation, at least one other researcher recorded key ideas emerging from the discussion and raised follow-up questions as needed. We made video recordings of focus groups unless a participant objected, in which case we utilized an audio recording. Focus groups varied from two-to-nine participants.

Sampling. Our sample reflects both purposive and convenience strategies. Our selection of a research site was purposive since it allowed access to student affairs professionals from a wide-range of backgrounds. Within that site, participants volunteered based on an overview shared prior to the conference and in the official program, which may mean that they are likely to have already had an interest in disability. Participants for the seventh focus group and the final debriefing section were recruited via emails sent to the student affairs division at each institution. In total, our sample included 31 participants from 21 higher education institutions across New England. In order to safeguard the anonymity and confidentiality of participants who were speaking candidly about a difficult topic, we refer to them by pseudonyms throughout. We summarize participant information in Table One.

\section{-- Insert Table One --}

Analysis. Our analysis utilized a grid analysis following each focus group. Utilizing the questions in our protocol as the framework, we sorted responses into a grid consisting of positive and negative phenomena (Morgan, 1996). We then examined variations within each focus group, across focus groups, within each question, and across questions. When themes reoccurred or helped to contextualize other findings, we included those preliminary analyses in our final conference session presentation. Since many focus group participants attended that final session, 
it also functioned as form of member checking that helped to draw out connections among key ideas and suggested areas of pressing concern (e.g., legal issues, professional development). Since we were concerned that our sampling strategy might have influenced our findings, we conducted one additional focus group and one debriefing session following the conference. Data from these sessions aligned with the prior focus groups and served as a form of triangulation.

Once transcriptions of all seven focus groups were complete, we engaged in constant comparative analysis (Charmaz, 2006). We generated open codes of the transcripts based on the meanings generated by participants. In this process, we also used, but were not limited to, preliminary themes from our grid analysis at the conference. We employed a structured coding process wherein one person provided an initial analysis of each transcript and then the coding was confirmed by at least one other team member. We then sought connections among open codes to generate focused codes and again among our focused codes to generate axial codes. Finally, we sought to understand our axial codes as part of a holistic process to generate the themes we present in our findings section and the model described in the discussion section.

Limitations. Our study has several limitations that should be considered when evaluating findings. First, our focus group sessions quickly moved toward consensus and may understate the variety of opinions held by participants. Furthermore, participants who self-selected into participation may actually possess more knowledge of disability than the average student affairs practitioner. Second, participants in our study were drawn from a narrow geographic region. It is possible that factors such as differences in accrediting bodies and access to professional development opportunities might produce regional variation in findings. Additionally, the limited racial and ethnic diversity represented in our sample is consistent with the student affairs workforce in the area where the data was collected but would likely differ elsewhere. Third, the 
majority of our participants were drawn from private institutions. Variations in work environment could well produce different findings. Finally, our study consisted primarily of student affairs practitioners whose primary responsibility is not working with students with disabilities. While this sample is appropriate for examining the general understanding of students with disabilities, we would have gained different information by focusing on practitioners who are more expert in working with students with disabilities.

\section{Findings}

Our analysis produced three major themes. First, participants report that responding to issues of disability effectively is complicated due to the large numbers of "moving" parts associated with providing effective support. Second, findings suggest that core values and transferable skills become the basis for effective practice. Third, participants describe a desire to alter the status quo by moving beyond "small wins" and toward systematic change.

\section{Too Many “Moving Parts"}

Across the seven focus groups, participants consistently described feeling unprepared to support students with disabilities. These feelings originated from a self-identified lack of knowledge about the law and appropriate accommodations. We began each focus group by asking participants: "How do you define disability?" Participant conversations quickly moved from this question to frustration regarding their own lack of understanding of how best to support students with disabilities. Highlighting the lack of clarity regarding the issue, one participant, who had just come from a workshop focused on supporting students with disabilities, joked, "Can I use my notes?" Very few participants were familiar with the legal definition of disability. In a statement that provides an apt summary of the thoughts of fellow participants, Jayden said, "I'm not going to get it exactly right but I know the law for ADA, or whatever, is anything that 
significantly affects a significant life function or something like that.” This quote, which includes both references to external authority and the acknowledgement of a lack of precision in application, highlights the use mixture of expert knowledge, personal experience, and conventional wisdom to shape the practices student affairs professionals employ when working with students with disabilities. When further encouraged to share their own definitions of disability, most participants generally described "physical and mental" conditions and referenced some sort of limitation. For instance, Morris defined disability as "something either a physical or mental that prevents them from doing everything they want to do or being able to fully participate in." Ajani said, "It's a medical condition that alters the way someone sees the world or interacts with the world." These definitions do indeed reflect frequently used medical and legal thinking, but they typically explain disability in terms of the individual rather than the societal structures that make the disability contextually salient.

Even while providing these definitions, student affairs also wrestled with assumptions of non-normativity and negativity surrounding the disability label. They raised troubling implications about how labels are applied, and by whom. Isabella described her definition as "any type of difference in ability or physical ability or one that's different from what's considered to be the majority." A student on the autism spectrum prompted Teshi to question societal definitions of disability and what was considered normative. She explained:

[The student asked] "Since when did thinking differently become a disability?" And it made me smile because I think a lot of what we view as disability is based on our cultural perceptions of what should be okay and what shouldn't be. But, since when did being rigid and sort of needing concrete structure laid out become something that was unacceptable? To that student they're quirky ... just a little different, but it's not 
something that requires accommodating because they got to college just like any other student . . . they have been labeled with something that everyone else thinks is a disability. But to them it's just who they are, it isn't something that needs to be fixed. Teshi's comments highlight the socially-constructed nature of disability. While only some participants in our study could identify this idea directly, all appeared to agree with it once they heard it express by others.

The lack of definitional clarity also provided our first introduction to the complex ways which participants wrestled with disability in student affairs practice. Even those with a rudimentary understanding of law discussed how a lack of clarity in policy language, combined with each student's unique situation, led to confusion over appropriate interventions. One focus group conversation summarized these concerns:

Ian: The other piece, the situations that come up are so varied . . . it's hard to have that cookie cutter approach, because every situation is so unique.

Layla: That term "reasonable" is so ... It's so grey. . . The law says this, but reasonable is so grey [and who is] the authority of what's reasonable? [. . . I think that the challenge that we have is that we've come a long way. . [but] we have more people ... that are going to require combinations [of support].

Ian and Layla highlight the multi-dimensional nature both of disability and the way it is encountered in student affairs. Since student affairs work extends well beyond the classroom, complicated and unique student circumstances often led to confusion surrounding reasonable accommodations. Morris agreed with this sentiment saying: "what is reasonable to one is not reasonable to another." Fabio further unpacks this idea by suggesting that students with the same 
"disability" could need different accommodations to succeed. He also described how two practitioners might support the same student differently. Fabio stated:

The same disability—how do you deal with it? How I deal with it? . It's all individual too. It's not just a blanket okay, this [is the appropriate accommodation]. . .You can't do that. It's the whole big picture and then there's every single moving part of it.

For student affairs practitioners, good responses to students with disabilities include not just sensitivity to the individual but also to context and to their own practice. That does indeed create a system with many "moving parts."

\section{Core Values and Transferrable Skills}

In the focus groups, we asked practitioners to describe how they responded when a student disclosed a disability. In their responses, it became clear that participants were not always sure where to refer a student for support. Many participants struggled on campuses where services were siloed, requiring students and practitioners to go from office to office in search of services. Chloe lamented, "A thing that could be clearer, on our campus for students is who they can turn to." Participants described how they (and most of their well-intentioned colleagues) were either unaware of campus resources and/or had no idea how to navigate the array of services located in different departments. Karma explained:

I don't know that many of my colleagues would have any idea even where to start. . I I work with a very caring - I mean these people go out of their way. But, I just don't think that the vast majority have been trained on what is available and what we could offer. In response, virtually all of our participants described efforts to do the best that they could based on the limited information that they had. To do so, they drew upon core professional values (e.g., empathy, validating student realities, challenging bias, serving as role models) and pre-existing, 
transferrable skill sets (e.g., helping, advising, coaching, problem solving) to support students.

Participants employed these strategies not because they knew them to be "best practices" in disability services per se, but instead because they knew them to be effective from other areas of their student affairs work. For instance, Thelma, a senior student affairs officer, described it best when she revealed that she taught students (and her staff) to utilize basic problem solving skills as they worked toward disability solutions and inclusion. Thelma shared, "So I see my role as trying to help them problem-solve." While problem-posing is a common advising technique, it is also fundamentally consistent with the respect for persons that undergirds good practice with students with disabilities.

Daylin explained how she used a specific phrase when students disclosed personal information to her-including a disability. This strategy aligned with her core professional value of treating all students with compassion and honoring their personal disclosures. Daylin describes using a verbal script to allow her time to process information shared with her by students: "The phrase that . . I use as my instant phrase. It's usually, “Okay, thank you for trusting me with that.". . That's become the statement that I say frequently, because it buys me a second to think about—What am I going to do? How do I help?" While this practice emerged from working with other student populations, Daylin's use of it as a transferable skill for supporting students with disabilities is quite common. Ajani likewise described using helping skills when working with students with disabilities_ noting: "Once they made that disclosure ... you're just trying to figure out what is the first step in the helping process."

While general descriptions of helping skills of the sort provided by Daylin and Ajani were relatively common, some participants described connections to specific practice models. For example, Fabio found appreciative advising methods to be effective. He stated: 
My first meeting with students is essentially an intake appointment to learn. We can share enough about each other that we're comfortable sharing — but really developing this relationship so when topics come up I can make really appropriate referrals or get them connected to resources ... the appreciative advising model has been really helpful ... Fabio's goal in advising conversations was to gain student-specific knowledge that allowed him to tailor educational interventions; appreciative advising provided him a strategy for doing so. Other participants described using rehearsal and role-modeling to support students with disabilities. Morris also stated that he drew upon existing skills when coaching students with disabilities so they can practice interactions before they encounter potentially challenging situations in other offices. As noted above, these challenging situations exist in part due to the disjointed infrastructure on many campuses. In the face of these obstacles, many participants served as role models and sought to challenge bias on campus. When asked about leadership for disability issues on their campuses, most participants named the disability services director or students. None described him/her/hirself as a campus leader. Yet, as we listened to participant narratives, it was clear they exhibited leadership by role modeling inclusion on campus-a finding that was true for practitioners at all levels, not just senior leaders. In a clear example, Dominic explained his desire to role model inclusive language and commitment to educating students when they used offensive terms such as "crazy" or "retarded." Summing up his approach to working with students, Dominic said:

Very important for me —is my language. . .language that I choose and also . . . the way that I speak to every student, or every person that I encounter. Because whether it's visual, or an invisible disability you never want to talk to somebody in a way that's [exclusionary or disrespectful]. . Any time I hear a student use the R-word I'm like, 
"Why did you use that? What was the thought behind that?" Trying to be as informative and informational as possible.

Dominic's example highlights the subtle way that, while not positional leaders for disabilityrelated issues on campus, many participants took an active role in creating a supportive campus.

For many, the desire to be a role model stemmed from personal experience with disability. Eight participants identified as having a disability, and of these, several explained how they aspired to be visible role models to students with disabilities. Through disclosure, Nelton, tried to convey the message "You're not different, you're perfectly normal, you can do whatever you want to do." Palmer, who recently began to identify as a person with a disability, shared how important it was to be visible. He stated, "Since I've gotten a disability, I think that I'm more intentional about it. I find myself trying to be more visible." Anna also disclosed her disability to validate student experiences and to show students they were not alone:

I had a student who was suffering from very severe depression and anxiety. Her parents were telling her that it wasn't a real thing. . . So I was able to be there, be like, "No it's real. I've been dealing with it since I was 16.”. . I can tell you there are these services on campus. I used them when I was an undergrad student. And just being able to like make it seem real. . . .rather than what her parents were saying that it was all in her head. That was a really important thing for me. I think sharing your story is so important.

Once again, the rapport that Anna developed through her own act of disclosure mirrors the behavior of student affairs professionals with regard to other aspects of student affairs experience. In sum, participants drew upon core values and utilized their pre-existing skills to support students on a case-by-case basis.

\section{Commitment to Campus Change: Moving Beyond "Small Wins"}


While most participants expressed skepticism that they were doing the right things to support students with disabilities, they were also certain that their campuses could do more. Parker, for example, described campus support as driven by the "small wins" achieved by supporting individual students as opposed to campus-wide inclusion for students with disabilities. He stated, "I think that in other [student affairs functional] areas, we look at best practices. . In disability services, you only look at small wins.” Like other participants, Parker expressed a deep commitment to ensuring he could best support students with disabilities, but he also wanted his institution to do better. While the strategies that participants describe for campus change vary more than for any other theme, they fall into three categories of increasingly transformative impact: self-directed education, collaboration, and a movement toward proactive campus practices.

Self-directed education. The vast majority of participants did not encounter disabilityrelated topics in their graduate preparation programs, and of those that did, the coverage was typically cursory. In a typical example, Isabella described her program's treatment of disability as a "one 3-hour lecture ... never an entire class." The one notable exception was legal issues courses, which though taken infrequently tended to provide more comprehensive coverage. Participants noted that their legal training was quickly out of date and required constant updating. To do so and to counteract their lack of preparedness, participants described engaging in self-directed educational activities. They attended professional development workshops, webinars, and sought information from colleagues on and off campus. Tabitha explained: I've probably mostly accessed resources through webinars and conferences. . .Myself and the director of disability services and director of international student services just did a webinar on students and crisis and suicidal students on our campus... We had a really 
big webinar last year. . It was everything that has happened in the past 2-5 years around this topic...You have to keep up.

Tabitha's example highlights both the need for trainings and the willingness of those who have some knowledge to share it others-a sentiment echoed by Chloe's experiences. When a student with Asperger's syndrome moved into her residence hall, Chloe took the initiative do independent research about the diagnosis. She said, "I had to do a lot of research to [learn] how I could best interact with the student." Chloe also relied on "conversations with [colleagues]. . to make up the difference" or shortcoming in her knowledge base.

Collaboration. Another way student affairs professionals felt they (and their universities) could better serve students with disabilities was to encourage collaboration among departments. As noted above, participants lamented the disjointed services on their campuses. Through collaboration, professionals could draw upon collective wisdom on campus to better meet student needs. Penny explained how effectively serving students with disabilities "requires a lot of collaboration and a lot of admitting that I don't know what the laws are or what the requirements are or what's needed.” Penny went on to note the remarkable range of institutional stakeholders that could be involved in addressing the needs of a student with a disabilityranging from general counsel to disability services to academic advising. While remarkable for the range of offices involved, participants often suggested that student affairs professionals were well-positioned to foster these collaborations. For example, Tabitha stated: "I think this is one of those areas where we talk about how in student affairs, we have to lead the way because no one else is going to do it." By virtue of the student affairs profession's long history as an institutional boundary-spanner, participants felt it was well-positioned to address the silo-busting needs of students with disabilities. 
Proactive versus reactive. Participants generally felt that there should not be a need to address student needs individually. They described the need for more proactive practices while also acknowledging that both they and their institutions were largely reactive at present. For many participants, reactive practice stemmed from a lack of knowledge. Palmer explained: "People don't know how to treat [students with disabilities] or be proactive." Isabella's statement elaborates on this idea by pointing out that students with disabilities were often "an afterthought and it's frustrating." This frustration served as a recurrent pattern throughout our focus groups, but it also often gave way to hope. As Tabitha asked: "What can you learn from those things? What can you do to just be more proactive - thinking ahead?" Likewise, Thelma argued that institutions needed to be more proactive because it was the "right thing to do" and argued that higher education needed to move beyond compliance and toward a place where we “do them [provide support] . . for everybody." The impulse toward inclusion and equity evident in Thelma's example served as the proposed catalyst for change in many participants stated hopes for their campus. For example, Autumn shared that:

retention ... has been a really huge focus because our incoming freshman class is smaller than it has been in the past. So, I have seen a much different focus from the university on the students that we wouldn't traditionally retain. So students who are having mental health issues, or students who may have a disability — who we may have in the past reached out to, but not as focused and intently as we have this year.

While budgetary constraints of the sort provided by a shrinking first year population make supporting students with disabilities more challenging from a fiscal perspective, it also serves to clarify the extent to which student needs have been neglected in the past. For many participants, that sort of demand for accountability seemed a positive direction forward. 
Participants also described putting proactive strategies into practice. For example, Abby shared how her student activities office was trying to get away from being purely reactionary. Instead of providing accommodations upon request, her office now proactively ensures "the venue is physically accessible. . . our movies have the option of closed captioning, or our speakers have interpreters." She and her colleagues also "work really hard to bring in acts that [include] people with disabilities." Other participants described similar initiatives in a way that recalls principles of universal design — albeit without using the term. One of the few student participants to use the term, Teshi, worked in a disability services office and said:

my office is big on universal design. . . a great example of that would be when we had a student with the hearing impairment who needs captioning. Other students benefit from captioning ... Is this an accommodation issue? Or is it a universal design thing? Why aren't we just designing things in a way where students can use multisensory ... ways of learning? And when you do that it's not "Oh there must be someone in the room who has a disability!" It's just this is what should happen.

Her quote demonstrates the connection between universal design and educational strategies that are good for everyone. It also highlights the potential of proactive support for students with disabilities.

\section{Discussion and Recommendations}

This action-based grounded theory study offers a snapshot into the experiences of student affairs professionals. Represented in Figure 1, our study revealed a dynamic process of action, reflection, and change analogous to informal theory (Reason \& Kimball, 2012) that led to more effective practices for supporting students with disabilities. Thirty-one professionals, representing intuitions across New England and all levels of student affairs, described how they 
felt unprepared to support students with disabilities. Represented by the "Limited Graduate Training" box in our model, that lack of preparation led student affairs professionals to repurpose existing knowledge—often in the form of "Core Values \& Transferable Skills" or "Effective Strategies for Practice" honed in their "Experience with All Students" - to better guide their "Interactions with Students with Disabilities." Nonetheless, all participants desired to move beyond "small wins" to campus-wide inclusion of students with disabilities. Consequently, participants described an ongoing "Commitment to Campus Change" through "Self-Directed Education," "Collaboration," and "Proactive Efforts."

-- Insert Figure One --

One important lesson that student affairs professionals may lack important information about disability policy, accommodations, and diagnoses among student affairs professionals. Our findings extend prior studies about SSAOs (Belch \& Marshak, 2006) and academic advisors (Preece et al. 2007) who expressed lack of knowledge about disability law. Our data suggest practitioners from a variety of functional areas and all positional levels (i.e., graduate student to SSAO), felt unknowledgeable and unprepared. While there is a growing body of non-empirical resources about supporting students with disabilities (e.g., Evans, Assadi, \& Herriott, 2005; Vance et al., 2014), practitioners need and desire more education about these topics. In fact, many of our study participants explained how they planned to attend all disability-related sessions at the NASPA conference. Yet, there were very few options. As a field, we need to offer more professional development opportunities, empirical studies, and graduate-level curriculum about disability topics. In addition to specific disability-focused knowledge, scholars and practitioners can infuse disability topics in workshops, graduate preparation classes, and 
empirical studies about all important topics in our field (e.g., student conduct, supervision, persistence, event planning)—not merely those with an explicit disability focus.

Participants in our study described the importance of drawing upon fundamental skills (e.g., helping, advising, coaching) to support students. These findings should prompt those who provide graduate preparation courses or professional development trainings to consider the importance of including disability topics into their teaching of foundational skills via case studies and other skill-building activities. Our data suggest it is important for emerging and seasoned professionals to learn that despite their lack of disability-specific knowledge, they can draw upon foundational skills to support students with disabilities.

These findings push beyond those of Preece et al. (2007) who found "genuine empathy was a secret to [academic advisor] success in working with students with disabilities” (p. 59). Our participants drew upon many core values (e.g., empathy, validating student realities, challenging bias, serving as role models, being proactive, and taking self-responsibility for learning) to support students. Participant perspectives largely aligned with many guiding principles Briodo and Reason (2001) found in 13 major philosophical statements in student affairs such as: holistic perspective, attention to individual differences, student agency, interactionist perspectives, intentionality and collaboration. Moreover, our participants exhibited one they found severely lacking in those documents. Reason and Broido argued "In addition to being service providers and educators, to be truly effective, student affairs professionals must explicitly embrace the roles of student advocate and social activist” (p. 376). In their quest to role model inclusivity, be proactive, and collaborate to create inclusive environments for students with disabilities (while simultaneously meeting individual needs), our participants were acting as advocates and social justice activists. Additional empirical work on effective practices for 
supporting students with disabilities would aid this work. Our study as well as past work (Evans et al., 2005) suggests that research focused on how students with disabilities relate both to student affairs practitioners with disabilities and allies without disabilities would be helpful.

While very few of our participants used the term universal design, most of them described perspectives and actions that resemble UD principles (The Center for Universal Design, 1997). Many attempted to create programs, services and environments that promoted equitable and fair use for all students. These findings align with our perspective that key universal design strategies have long been used by student affairs professionals - even if not explicitly labeled as such (e.g. Kuh et al., 2005; Strange \& Banning, 2000). We recommend that student affairs preparation faculty and supervisors role model the use of UD in a more intentional, systematic way. A number of best practice writings offer general suggestions UD implementation (Burgstahler, 2008), while others focus on specific functional areas (Vance et al. 2014) or populations such as students with Asperger's syndrome (Taylor \& Colvin, 2013). Our empirical findings provide support for UD literature that suggests all professionals have the responsibility and capacity to create services, programs, and environments that are useful and inclusive to all students, not just students with disabilities.

\section{References}

Belch, H. A., \& Marshak, L. E. (2006). Critical incidents involving students with psychiatric disabilities: The gap between state of the art and campus practice. Journal of Student Affairs Research and Practice, 43(3), 840-859.

Buchanan, T., Charles, M. S., Rigler, M., \& Hart, C. (2010). Why are older faculty members more accepting of students with attention-deficit hyperactivity disorder? A life-course 
interpretation. International Journal of Disability, Development \& Education, 57(4), $351-369$.

Burgstahler, S. E. (2008). Universal design in higher education. In S. E. Burgstahler \& R. C. Cory (Eds.), Universal design in higher education: From principles to practice (pp. 320). Cambridge, MA: Harvard University Press.

Charmaz, K. (2006). Constructing grounded theory: A practical guide through qualitative analysis. Thousand Oaks, CA: Sage.

Cook, L., Rumrill, P. D., \& Tankersley, M. (2009). Priorities and understanding of faculty members regarding college students with disabilities. International Journal of Teaching and Learning in Higher Education, 21(1), 84-96.

Eilola, C., Fishman, K., Greenburg, A., Moore, C. D., Schrijver, A., \& Totino, J. (2011). Success with ACCESS: Use of community-based participatory research for implementation. Journal of Postsecondary Education and Disability, 24(1), 61-65.

Evans, N. J., Assadi, J. L., \& Herriott, T. K. (2005). Encouraging the development of disability allies. In R. D. Reason, E. M. Broido, T. L. Davis, \& N. J. Evans (Eds.), Developing social justice allies, (pp. 67-79). New Directions for Student Services, 110. San Francisco, CA: Jossey-Bass.

Izzo, M. V., Murray, A., \& Novak, J. (2008). The faculty perspective on universal design for learning. Journal of Postsecondary Education and Disability, 21(2), 60-72.

Hernandez, C. (2011). Developing grounded theory using focus groups. In V. B. Martin \& A. Gynnild (Eds.), Grounded Theory: The Philosophy, Method, and Work of Barney Glaser (pp. 117-32). Boca Raton, FL.: BrownWalker.

Hitchings, W. E., Retish, P., \& Horvath, M. (2005). Academic preparation of adolescents with 
disabilities for postsecondary education. Career Development for Exceptional Individuals, 28(1), 26-35.

Jones, S. R. (1996). Toward inclusive theory: Disability as social construction. NASPA Journal, $33,347-354$.

Junco, R., \& Salter, D. W. (2004). Improving the campus climate for students with disabilities through the use of online training. Journal of Student Affairs Research and Practice, $41(2), 462-475$.

Kaplin, W. A., \& Lee, B. A. (2013). The law of higher education (5 ${ }^{\text {th }}$ Ed.). San Francisco, CA: Jossey-Bass.

Kimball, E., Wells, R., Ostiguy, B., Manly, C. \& Lauterbach, A. (in press). Students with disabilities in higher education: A review of the literature and an agenda for future research. In M. Paulsen (Ed.) Higher Education: Handbook of Theory and Research. New York: Springer Publishing.

Lombardi, A. R., \& Murray, C. (2011). Measuring university faculty attitudes toward disability: Willingness to accommodate and adopt universal design principles. Journal of Vocational Rehabilitation, 34(1), 43-56.

Morgan, D. L. (1996). Focus groups as qualitative research (2nd ed.). Thousand Oaks, CA: Sage.

Peña, E. V. (2014). Marginalization of published scholarship on students with disabilities in higher education journals. Journal of College Student Development, 55(1), 30-40.

Preece, J. E., Roberts, N. L., Beecher, M. E., Rash, P. D., Shwalb, D. A., \& Martinelli, E. A. (2007). Academic advisors and students with disabilities: A national survey of advisors' experiences and needs. NACADA Journal, 27(2), 57-72. 
Reardon, K. M. (1998). Participatory action research as service learning. In R. A. Rhoads \& J. P. F. Howard (Eds.), Academic service learning: A pedagogy of action and reflection (pp. 57-64). New Directions for Teaching and Learning, 73. San Francisco, CA: Jossey-Bass.

Reason, R. D. \& Broido, E. M. (2011). Philosophy and values. In J. H. Schuh, S. R. Jones, \& S. R. Harper, S. R. (Eds.) Student services: A handbook for the professions (5th ed.) (pp. 8095). San Francisco: Jossey-Bass

Reason, R. \& Kimball, E. (2012). A new theory-to-practice model for student affairs: Integrating scholarship, context, and reflection. Journal of Student Affairs Research \& Practice, 49(4), 359-376.

Shakespeare, T. (2012). Still a health issue. Disability and Health Journal, 5(3), 129-131.

Swain, J., \& French, S. (2000). Towards an affirmation model of disability. Disability \& Society, 15(4), 569-582.

Taylor, C. M. \& Colvin, K. L. (2013). Universal design: A tool to help college students with Asperger's syndrome engage on campus. About Campus, 18 (3), 9-15.

The Center for Universal Design (1997). The principles of universal design, version 2.0. Raleigh, NC: North Carolina State University. Retrieved from: http://www.ncsu.edu/ncsu/design/cud/about_ud/udprinciplestext.htm

United States Government Accountability Office. (2009). Higher education and disability: Education needs a coordinated approach to improve its assistance to schools in supporting students. Retrieved from: http://www.gao.gov/assets/300/297433.pdf.

Vance, M. L., Lipsitz, N. E., \& Parks, K. (Eds.). (2014). Beyond the Americans with disabilities act: Inclusive policy and practice for higher education. Washington, D.C.: NASPA. 